Posfácio/Postscript

\title{
O Dicionário de Lingüística e Gramática: Notas de um Leitor-Posfaciador
}

(The Dictionnary of Linguistics and Grammar:

Notes from a Reader and a Posface Writer)

Francisco Gomes de MATos

(UFPE)

Este importante legado mattosiano tem uma história singularíssima: foi lançado em 1956, pelo Centro de Pesquisas da Casa de Rui Barbosa (RJ), com o título de Dicionários de Fatos Gramaticais (DFG); em 1965, J. Ozon-Editor (RJ) publicou a segunda edição, intitulada Dicionário de Filologia e Gramática e, em 1977, postumamente, a Editora Vozes (Petrópolis, RJ) publicou a sétima edição, sob o título atualizado de Dicionário de Lingüística e Gramática (DLG). Ao que saiba, trata-se de um caso único na bibliografia lingüística brasileira: uma obra de referência receber três títulos, reflexo do desenvolvimento da ciência da linguagem entre nós.

Aos interessados em conhecer detalhes da expressiva e inspiradora obra mattosiana - aqui relembrada neste auspicioso volume comemorativo do centenário do saudoso amigo-mentor-colega, de quem tive o privilégio de ser aluno, no I Instituto Latino-Americano de Lingüística em Montevidéu, realizado na Universidad de la República, sob os auspícios do PILEI, Programa Interamericano de Lingüística e Ensenãnza de Idiomas; estivemos juntos, como docentes, no memorável Instituto Interamericano de Lingüística no México (janeiro-fevereiro de 1968) e em outros eventos, no Brasil e no exterior, - recomendo a leitura dos textos Sinopse dos Estudos Lingüísticos no Brasil (Hamilton Elia); Biobibliografia, Nota dos Editores para a 7a. edição; Advertência para a 3a. e 2a. edições e, Explicação Preliminar da 1a. edição, no volume póstumo de 1977, com sucessivas edições até esta data. 
Para dar uma idéia da importância desses textos que antecedem o corpus lexicográfico do DLG, formulo três perguntas cujas respostas podem ser encontradas através da leitura atenta da Explicação Preliminar da 1a. edição: 1) Qual o sentido de fatos, na locuçãofatos gramaticais? 2) Quantas vezes fatos ocorre no referido texto e em que contextos? 3) A quem Mattoso agradece, com elevado senso de humildade autoral? Fosse o grande pioneiro da Lingüística no Brasil atualizar seu uso de fatos gramaticais, que termo poderia ter usado? Talvez conceitos lingüísticos e gramaticais, ou, mais ao gosto dos colegas que atuam na importantíssima área da Terminologia (ciência dos termos), "Dicionário de terminologia lingüístico-gramatical". Especulando mais um pouco: em vez de optar por emprego, à página $31 \mathrm{da}$ citada Explicação, Mattoso refere-se à "compreensão do funcionamento da língua a cujo bom emprego se pretende chegar". Atualmente, emprego poderia ser substituído por uso. Ainda sobre esse uso mattosiano de emprego, chamo atenção para o verbete sobre tal conceito: ali, com antecipador senso sociolingüístico, o autor do também pioneiro e longevo Manual de Expressão Oral e Escrita estabelece uma tipologia de usos, ao explicar: "Há empregos usuais, inusuais e inadequados" (p.104). Falar de empregos usuais e inusuais não surpreende tanto, mas referir-se a empregos inadequados constitui gratíssima surpresa para quem consultar o DLG neste ano de 2004.

Ao comentar sobre alguns aspectos da singularidade do DLG, não posso deixar de me referir à magistral capacidade comunicativa mattosiana: seu português escrito é erudito, formal, elegante. Por falar em uso erudito, há um verbete sobre vocábulos eruditos (p. 108), no qual são exemplificados contrastes de uso léxico. Assim, ao lado dos substantivos populares pobre, ouro, temos os adjetivos eruditos paupérrimo e áureo.

Uma coisa admirável nesse dicionário é sua bibliografia multilíngüe: há fontes em português, francês, inglês, espanhol, alemão e italiano. Outra exemplaridade da obra! Quanta coisa de interesse socioestilísticolingüístico-pragmático pode ser encontrada no DLG! Como Mattoso poderia ter atualizado seu repertório conceitual-terminológico, decorridos quase cinqüenta anos da publicação de seu DLG?

Devo ter começado a usar o pioneiríssimo Dicionário de Lingǘstica e Gramática, do saudoso amigo-mentor Mattoso (assim a ele me dirigia) em meados da década de 50, quando eu cursava o Bacharelado em Letras 
Anglo-Germânicas na Faculdade de Filosofia da então Universidade do Recife. Três coisas me atraíam naquele volume: 1) ser identificado como "Referente à língua portuguesa": tenho a impressão de que muitos poucos leitores param para refletir sobre a importância desse subtítulo, tanto para a bibliografia lingüística em português, quanto para a história da formação lingüística de professores de nosso idioma; 2) a qualidade estilística dos verbetes: Mattoso produz um português erudito, que sociolingüisticamente poderíamos caracterizar como sendo uso formal. Assim, no verbete língua, lê-se: "[...] sistema de sons vocais por que se processa numa comunidade o uso da linguagem humana" (DFG, p. 158) interdisciplinaridade subjacente a diversos conceitos-termos. Exemplifico: "A linguagem é uma faculdade imensamente antiga da espécie humana e deve ter precedido os elementos mais rudimentares da cultura material” (p. 159). Essa afirmação mattosiana, inspirada em Sapir (1954), reflete um pouco a influência da Psicologia daquela época, em que se optava por faculdade. Hoje, muitos prefeririam dizer sistema cognitivo. Para a ocorrência do adjetivo mental em DLG, veja-se o verbete comunicação (p. 77). Para conceitos de áreas afins, consulte-se estilística (p. 110), folclore (p. 117), retórica (p. 209).

Coube ao notável franciscano Clarêncio Neotti (amigo de Mattoso, de sua esposa Maria Irene e deste articulista) a tarefa de relatar, em Nota dos Editores para a 7a. edição (1977), como surgiu a idéia de acrescentar-se um Posfácio ao DLG. Nas palavras do referido teólogo, atualmente residente em Roma: "Ao aceitar o pedido de Dona Maria Irene Ramos Câmara, viúva de Joaquim Mattoso Câmara Jr., de continuar a publicação do livro, lhe fizemos duas propostas: o acréscimo de um posfácio com os principais termos lingüísticos desenvolvidos após a morte do Prof. Mattoso Câmara (1970); e a mudança do título para Dicionário de Lingüística e Gramática. Dona Maria Irene concordou com ambas as propostas" (p. 25). Em seguida, o ex-Diretor da revista Cultura Vozes (que a Mattoso dedicou um número em sua homenagem ), justifica a generosa escolha deste articulista para escrever o posfácio: "por ser bom conhecedor, como ex-discípulo e amigo de Mattoso Câmara, de toda a obra de quem já foi chamado de Pai da Lingüística no Brasil" (p. 26). Esse fato marcou profundamente minha missão como lingüista. $\mathrm{Na}$ verdade, ter sido convidado a acrescentar verbetes ao DLG foi mais que um imenso desafio profissional: oportunizou que, privilegiadamente, tivesse meu nome incluído numa obra de meu antigo mestre e que pudesse compartilhar, com os usuários daquele volu- 
me, um pouco do conhecimento que eu vinha construindo em meu trabalho como lingüista aplicado.

Graças a essa oportunidade única, pude expor alguma coisa de minhas atitudes, crenças e antevisões (consulte-se o verbete lingüistica bumanístical bumana, em que formulei a idéia embrionária do que, no início da década de 90, viria a chamar "paz comunicativa" e, no início deste século, "Lingüística da Paz" (cf. meu livro Comunicar para o Bem. Rumo à Paz Comunicativa. São Paulo: Editora Ave Maria, 2002).

Dificílima foi a decisão de quantos verbetes incluir no Posfácio e por quê. Para que os leitores possam avaliar o produto final -25 verbetes e 62 referências suplementares (de livros, artigos, revistas); organizações atuantes na Lingüística no Brasil (ABRALIN, GEL, dentre outras); informação sobre universidades brasileiras que ofereciam programas de pós-graduação em Lingüística; lista de organizações internacionais, Biblioteca Mattoso Câmara - esclareço que, em 1997, já tinha concluído minha pós-graduação em Lingüística (Mestrado pela University of Michigan, Ann Arbor, EUA e doutorado pela PUC-SP), tendo sido aluno de lingüistas no exterior, dentre os quais Fries, Gumperz, Halliday, Lado e Pike.

Ao consultar-se o DLG, vale lembrar que, por formação, Mattoso era um estruturalista-funcionalista, com forte pendor para a interdisciplinaridade, em parte devido à influência recebida de seu notável mestre Roman Jakobson e, em parte, por causa do impacto do pensamento sapiriano (Mattoso traduziu um dos clássicos da Lingüística contemporânea: A Linguagem. Introdução ao Estudo da Fala, de Edward Sapir, publicado há 50 Anos pelo Instituto Nacional do Livro, Rio de Janeiro). Aos interessados em outros detalhes biográficos, recomendo a leitura da Biobliografia, na edição póstuma do DLG, e da Sinopse dos Estudos Lingüísticos no Brasil (Hamilton Elia), além do indispensável magistral volume organizado por Cristina Altman sobre a Pesquisa Lingüística no Brasil (1968-1988), publicado pela Editora Humanitas, da Universidade de São Paulo.

Quais os 25 verbetes acrescentados ao DLG? Aceitabilidade, aplicada (Lingüística), aquisição da linguagem, casos (gramática dos), competência, competência comunicativa, criatividade lingüistica, desempenho (atuação ou performance), distintivos (traços), empatia comunicativa, estratificacional (gramática), formal (uso), glossemática, gramaticalidade, humana (Lingüística), informal (uso), 
neutro (uso), padrão, paráfrase, pragmática, profunda (estrutura), psicolingüística, semiótica, sociolingüística, usuário (gramática do). Fosse atualizar o Posfácio, certamente incluiria gramática do português falado, análise do discurso, ecolingüística, lingüística de corpus, lingüística bistórica, lingüística cognitiva, lingïística da paz, história / bistoriografia da lingüística, teoria da comunicação (o DLG menciona esse termo, no verbete encodização), variedade (o DLG inclui um verbete para variação, no qual são exemplificadas variantes (do fonema, do morfema, do semantema e de padrões frasais). O conceito 'variedade' teria seu lugar ao sol terminológico, pois a variação se manifesta através de variedades (geográficas, sociais, individuais, históricas) e estas se concretizam, por assim dizer, através de variantes (léxicas, sintáticas, pragmáticas, etc). Observe-se, entretanto, que em seu verbete registro, Mattoso assim usa variedades: "As variedades no registro abrangem todos os níveis da língua - o léxico, a morfologia, a sintaxe, a estilística”. Ao escolher registro, Mattoso estava sob influência da terminologia do que ele identificou como 'Escola Lingüística de Londres' (veja-se o verbete escola, no qual são explicitadas seis escolas: a neogramática, a de Praga, Londres, Yale, M.I.T e Genebra). Aos que admiram a contribuição chomskiana à lingüística, lembraria que, no verbete sobre escola, Mattoso refere-se à escola Gerativa ou Transformacional. Aos pesquisadores da importante área de estudos tradutórios, recomendo a consulta ao verbete transformação (p. 234), no qual Mattoso exemplifica alguns casos de "transformação em frases equivalentes".

Finalmente, como o DLG, patrioticamente, tem o subtítulo Referente à Lingua Portuguesa, recomendaria a leitura do verbete português (Mattoso faz magistral Síntese da história de nossa língua) que, hoje, atualizaríamos com a bibliografia tão diversificada disponível, sob forma impressa e eletrônica (cf. o site da Comunidade de Povos de Língua Portuguesa (CPLP): www.cplp.org).

Em suma, como leitor e privilegiado prefaciador (neste caso, por generosidade da saudosa Maria Irene Câmara, da Editora Vozes e por bondade divina ), poderia contar muito mais. Em vez disso, convido os leitores a uma leitura ou re-leitura do Dicionário de Lingïística e Gramática, um marco na história/historiografia da Lingüística em língua portuguesa e um legado inestimável de quem tanto a amou (Mattoso começou como professor do que, na época, se chamava língua pátria) e, após obter o grau de arquiteto, dedicou-se à ciência da linguagem. Mattoso Câmara foi mais 
que um humanista: humanizador, através de suas obras, de caráter descritivo e didático, cuja longevidade comprova a relevância sustentável do pensamento mattosiano.

Em 1966, tive o privilégio de resenhar o DLG na revista HISPANIA (p. 181:182), da American Association of Teachers of Spanish and Portuguese. Decorridos 28 anos, escrevo estas notas, como leitor-posfaciador. Outro privilégio, entretanto, continuará: o de ser usuário fiel do DLG, por seu pioneirismo, seu foco na língua portuguesa, e pela erudição-concisão-exatidão com que Mattoso partilha com tantas gerações seu saber lingüísticogramatical.

E-mail: fcgm@hotlink.com.br 